\title{
A Study of Velocity and Temperature Slip Effects on Flow of Water Based Nanofluids in Converging and Diverging Channels
}

\author{
Syed Tauseef Mohyud-Din • Umar Khan • \\ Naveed Ahmed • Waseem Sikander
}

Published online: 13 February 2015

(C) Springer India Pvt. Ltd. 2015

\begin{abstract}
Copper (Cu) and silver (Ag) nanoparticle are added to water as a base fluid to study the effects of velocity and temperature slip on the flow between converging and diverging channels. A similarity transform has been employed to reduce the nonlinear partial differential equations to a system of nonlinear ordinary differential equations which is then solved by using two analytical schemes variational iteration and variation of parameters methods. For the sake of comparison, a numerical solution using fourth order Runge-Kutta method (RK-4) is also presented. Effects of velocity slip, temperature jump and the other parameters on the flow are discussed and demonstrated graphically. Comparison with already existing results in literature shows the efficiency of the method used.
\end{abstract}

Keywords Nanofluids - Slip conditions - Heat transfer · Variational iteration method $(\mathrm{VIM}) \cdot$ Variation of parameters method $(\mathrm{VPM}) \cdot$ Diverging and converging channels

\section{Introduction}

Pure water, kerosene oil, ethylene and glycol inherently are the poor conductors of heat. To increase the thermal conductivity and other thermal properties of these fluids, over the years, many techniques have been used. One of these is to add an appropriate amount of some nano-sized particles to the fluids. Copper, silver, titanium and other nano-sized particles are used for this purpose. These nanoparticles are good conductors of heat and enable the base fluids to enhance their thermal properties. Many researchers have attempted to come up with a most general model that can be used to cope up with the above problems. Choi $[1,2]$, Buongiorno [3], Nield and Kuznetsov [4,5] and others presented some of the models that are currently being used to study different properties of nanofluids. Researchers have showed their continued interest to study different problems utilizingthese models [6-10].

S. T. Mohyud-Din ( $\varangle)$. U. Khan · N. Ahmed · W. Sikander

Department of Mathematics, Faculty of Sciences, HITEC University, Taxila Cantt, Pakistan

e-mail: syedtauseefs@ hotmail.com 
Flow through non parallel walls, inclined at an angle are of much importance in real world. Applications of these flows can be found in aerospace, chemical, civil, environmental, mechanical and bio-mechanical engineering. The model presented by Jeffery and Hamel $[11,12]$ has been used to describe these flows in different industrial and practical problems. Itprovides a drastically simplified model for the flows in rivers and channels. Many available studies have considered different properties related to this problem and have tried to investigate the flow characteristics by varying the angle between the walls [13-18]. These studies used no slip boundary condition at the walls to analyze the different aspects of fluid's velocity. Navier [19] suggested a more general boundary condition representing a fluid slip at the solid-liquid interface, according to which amount of liquid slip at the boundary is proportional to the shear stress at the wall. A constant of proportionality is also involved called the velocity slip parameter and has the dimensions of length. The applications of slip effect include, reduction of friction, energy conversation and mimicking biological water channels [20]. Many authors have shown significant interest in studying the slip effects in different geometries for different fluids [21-24].

Literature survey reveals that for Jeffery-Hamel flow, effect of velocity slip was first studied by Dorrepaal [25]. Same problem has been studied for different types of nanofluids using different base fluids by adding variety of nanoparticles. All these studies were carried out using no-slip boundary condition [26-28]. Recently, Khan et al, [29] presented a study regarding flow through converging and diverging channels incorporating velocity and temperature slip effects.

Inherent non-linearity of the equations governing the fluid flow and heat transfer makes the exact solutions of the problems least likely. To cope up with this problem, many analytical techniques have been developed and have been extensively used to study different non-linear problems governing physical phenomena [30-38]. Variation of parameters method (VPM) is one of these analytical techniques [39-41]. This techniqueneither requires any discretization nor does it dependonthe existence of small or large parameter to be implemented. This makes VPM an efficient, more user friendly and easy to implement. Many studies are available on applications of this method.

Purpose of this study is to deal with the combined effects of velocity slip and temperature jump on Jeffery Hamel flow with heat transfer. Viable similarity transformations have been used to convert the partial differential equations governing the flow into a system of ordinary differential equations. Water is used as a base fluid and copper and silver nanoparticles are added to study the effects of the slip parameters and other emerging parameters on the velocity and temperature profiles. Physical variations for both diverging and converging channels are presented with the help of graphs coupled with comprehensive discussions. VPM is used to solve the governing equations and comparisons are made between the present and already existing solutions.

\section{Governing Equations}

In this problem, we have considered an incompressible viscous fluid flow dueto source or sink at the intersection of two rigid plane walls. Angle betweenthe walls is $2 \alpha$ (Fig. 1). Flow is assumed to be symmetric and purely radial. They are embedded in a medium filled with water based nanofluids containing different types of nano particles i.e. copper $(\mathrm{Cu})$ or Silver $(\mathrm{Ag})$. The base fluids and the nanoparticles are assumed to be in a thermal equilibrium. It is also assumed that there is a slip between the base fluids and nanoparticles. Under these assumptions velocity field takes the form $\mathrm{V}=\left[u_{r}, 0,0\right]$, where $u_{r}$ - is a function of $\mathrm{r}$ and $\theta$ both. 
The equations of continuity,motion and energy in polar coordinates in absence of body forcesunder imposed assumptions become [29]

$$
\begin{gathered}
\frac{1}{r} \frac{\partial}{\partial r}\left(r u_{r}\right)=0 \\
\rho_{n f}\left(u_{r} \frac{\partial u_{r}}{\partial r}\right)=-\frac{\partial p}{\partial r}+\mu_{n f}\left[\frac{\partial^{2} u_{r}}{\partial r^{2}}+\frac{1}{r} \frac{\partial u_{r}}{\partial r}+\frac{1}{r^{2}} \frac{\partial^{2} u_{r}}{\partial \theta^{2}}-\frac{u_{r}}{r^{2}}\right], \\
-\frac{1}{\rho_{n f} r} \frac{\partial p}{\partial r}+\frac{2}{r^{2}} \frac{\mu_{n f}}{\rho_{n f}} \frac{\partial u_{r}}{\partial \theta}=0 \\
u_{r} \frac{\partial T}{\partial r}=\frac{k_{n f}}{\left(\rho C_{p}\right)_{n f}}\left[\frac{\partial^{2} T}{\partial r^{2}}+\frac{1}{r} \frac{\partial T}{\partial r}+\frac{1}{r^{2}} \frac{\partial^{2} T}{\partial \theta^{2}}\right]+\mu_{n f}\left[4\left(\frac{\partial u_{r}}{\partial r}\right)^{2}+\frac{1}{r^{2}}\left(\frac{\partial u_{r}}{\partial \theta}\right)^{2}\right] .
\end{gathered}
$$

Supporting boundary conditions are,

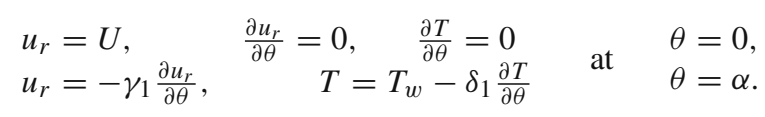

where, $T_{w}$ is the temperature at the wall, $\gamma_{1}$ and $\delta_{1}$ are the velocity slip and thermal slip parameters respectively.

From the equation of continuity (1), we can write

$$
f(\theta)=r u_{r}(r, \theta) .
$$

Dimensionless form of the problem can be obtained by using

$$
F(\eta)=\frac{f(\theta)}{f_{\max }}, \eta=\frac{\theta}{\alpha}, \beta(\eta)=\frac{T}{T_{w}} .
$$

Eliminating $p$ from Eqs. (2), (3) and using Eqs. (6) and (7), we get a system of nonlinear ordinary differential equations in terms of normalized velocity profile $F(\eta)$ and temperature profile $\beta(\eta)$,

$$
\begin{aligned}
& F^{\prime \prime \prime}(\eta)+2 \alpha \operatorname{Re}(1-\phi)^{2.5} A_{1} F(\eta) F^{\prime}(\eta)+4 \alpha^{2} F^{\prime}(\eta)=0, \\
& \beta^{\prime \prime}(\eta)+\frac{A_{2} E c \operatorname{Pr}}{A_{3}(1-\phi)^{2.5}}\left[4 \alpha^{2} F^{2}(\eta)+\left(F^{\prime}(\eta)\right)^{2}\right]=0 .
\end{aligned}
$$

Using Eqs. (6) and (7), the boundary conditions (5) become

$$
\begin{aligned}
& F(0)=1, F^{\prime}(0)=0, F(1)=-\frac{\gamma}{(1-\phi)^{2.5}} F^{\prime}(1) \\
& \beta(1)=1-\beta^{\prime}(1), \beta^{\prime}(0)=0 .
\end{aligned}
$$

Re here is Reynolds number given by:

$$
\operatorname{Re}=\frac{f}{v}=\frac{U r \alpha}{v}\left(\begin{array}{l}
\text { Divergent Channel: } \alpha>0, U>0 \\
\text { Convergent Channel: } \alpha<0, U<0
\end{array}\right) .
$$

Further, $E c=\frac{\mu c_{p}}{k}, \operatorname{Pr}=\frac{U^{2}}{c_{p} T_{w}}, \gamma=\frac{\gamma_{1}}{\alpha}$ and $\delta=\frac{\delta_{1}}{\alpha}$, represent Eckert number, Prandtl number, velocity slip parameter and the thermal slip parameter, respectively, also 


$$
\begin{aligned}
& A_{1}=\left((1-\phi)+\phi \frac{\rho_{s}}{\rho_{f}}\right), \\
& A_{2}=(1-\phi)+\phi \frac{\left(\rho C_{p}\right)_{s}}{\left(\rho C_{p}\right)_{f}}, \\
& A_{3}=\frac{k_{n f}}{k_{f}}=\frac{k_{s}+2 k_{f}-2 \phi\left(k_{f}-k_{s}\right)}{k_{s}+2 k_{f}+\phi\left(k_{f}-k_{s}\right)} .
\end{aligned}
$$

Physical quantities of interest are the skin friction coefficient and Nusselt number defined as:

$$
\begin{aligned}
C_{F} & =\frac{\mu_{n f}\left(\tau_{r \theta}\right)_{\eta=1}}{\rho_{n f} U^{2}}, \\
N u & =\frac{-l k_{f}\left(q_{w}\right)_{\eta=1}}{k T_{w}} .
\end{aligned}
$$

In terms of Eqs. (8)-(11), we have

$$
\begin{aligned}
\operatorname{Re}_{r} C_{f} & =A_{1}(1-\phi)^{2.5} F^{\prime}(1), \\
\alpha N u & =-A_{3} \beta^{\prime}(1) .
\end{aligned}
$$

\section{Solution Procedure}

\section{Solution Using VIM}

To solve Eqs. (9) and (10) with the associated boundary conditions (11) using VIM [33-39] the velocity and temperature can be written as,

$$
\begin{aligned}
& F_{n+1}(\eta)=F_{n}(\eta)+\int_{0}^{\eta} \lambda_{F}(s)\left(F^{\prime \prime \prime}(s)+4 \alpha^{2} \widetilde{F}^{\prime}(s)+(1-\phi)^{2.5} A_{1} 2 \alpha \operatorname{Re} \widetilde{F}(s) \widetilde{F}^{\prime}(s)\right) d s, \\
& \beta_{n+1}(\eta)=\beta_{n}(\eta)+\int_{0}^{\eta} \lambda_{\beta}(s)\left\{\beta^{\prime \prime}(\eta)+\frac{A_{2} E c \operatorname{Pr}}{A_{3}(1-\phi)^{2.5}}\left(4 \alpha^{2} \widetilde{F}^{2}(s)+\left(\widetilde{F}^{\prime}(s)\right)^{2}\right)\right\} d s,
\end{aligned}
$$

where, $\lambda_{F}(s)$ and $\lambda_{\beta}(s)$ are Lagrange multipliers for velocity and temperature profile respectively. We can get approximate Lagrange multipliers as $\lambda_{F}(s)=-\frac{(s-\eta)^{2}}{2 !}$ and $\lambda_{\beta}(s)=(s-\eta)$ so that the above iterative formula can be written as

$$
\begin{aligned}
& F_{n+1}(\eta)=F_{n}(\eta)-\int_{0}^{\eta} \frac{(s-\eta)^{2}}{2 !}\left(F^{\prime \prime \prime}(s)+4 \alpha^{2} F^{\prime}(s)+(1-\phi)^{2.5} A_{1} 2 \alpha \operatorname{Re} F(s) F^{\prime}(s)\right) d s, \\
& \beta_{n+1}(\eta)=\beta_{n}(\eta)+\int_{0}^{\eta}(s-\eta)\left\{\beta^{\prime \prime}(\eta)+\frac{A_{2} E c \operatorname{Pr}}{A_{3}(1-\phi)^{2.5}}\left(4 \alpha^{2} F^{2}(s)+\left(F^{\prime}(s)\right)^{2}\right)\right\} d s .
\end{aligned}
$$

Consuming boundary conditions, we can get

$$
F_{0}(\eta)=1+B \frac{\eta^{2}}{2}
$$




$$
\beta_{0}(\eta)=C
$$

where $\mathrm{B}$ and $\mathrm{C}$ are the constants to be determined later by using the slip boundary conditions for velocity and temperature profiles.

Next few terms of the solution are given as

$$
\begin{aligned}
& F_{1}(\eta)=1+B \frac{\eta^{2}}{2}-\frac{B^{2} \alpha \operatorname{Re} A_{1}(1-\phi)^{2.5} \eta^{6}}{20}-\left(B \frac{\alpha^{2}}{6}+B \frac{\operatorname{Re} \alpha A_{1}(1-\phi)^{2.5}}{12}\right) \eta^{4}, \\
& \beta_{1}(\eta)=C-\frac{2 E c \operatorname{Pr} \alpha^{2} A_{2}}{A_{3}(1-\phi)^{2.5}} \eta^{2}-\frac{B^{2} E c \operatorname{Pr} \alpha^{2} A_{2}}{30 A_{3}(1-\phi)^{2.5}} \eta^{4}-\left(\frac{B^{2} E c \operatorname{Pr} A_{2}}{12 A_{3}(1-\phi)^{2.5}}+\frac{B E c \operatorname{Pr} \alpha^{2} A_{2}}{3 A_{3}(1-\phi)^{2.5}}\right) \eta^{6}, \\
& F_{2}(\eta)=1+B \frac{\eta^{2}}{2}-\left(B \frac{\alpha^{2}}{6}+B \frac{\operatorname{Re} \alpha A_{1}(1-\phi)^{2.5}}{12}\right) \eta^{4} \\
& +\left(B \frac{\alpha^{4}}{45}-\frac{B^{2} \alpha \operatorname{Re} A_{1}(1-\phi)^{2.5}}{120}+\frac{B \alpha^{3} \operatorname{Re} A_{1}(1-\phi)^{2.5}}{45}+\frac{B \alpha^{3} \operatorname{Re}^{2} A_{1}^{2}\left((1-\phi)^{2.5}\right)^{2}}{1080}\right) \eta^{6} \\
& +\left(\frac{B^{2} \alpha^{3} \operatorname{Re} A_{1}(1-\phi)^{2.5}}{180}+\frac{B^{2} \alpha^{2} \operatorname{Re}^{2} A_{1}^{2}(1-\phi)^{2.5}}{560}\right) \eta^{8}+\ldots \\
& \beta_{2}(\eta)=C-\frac{2 E c \operatorname{Pr} \alpha^{2} A_{2}}{A_{3}(1-\phi)^{2.5}} \eta^{2}-\frac{B^{2} E c \operatorname{Pr} \alpha^{2} A_{2}}{30 A_{3}(1-\phi)^{2.5}} \eta^{4} \\
& +\left(\frac{B^{2} E c \operatorname{Pr} \alpha^{2} A_{2}}{90 A_{3}(1-\phi)^{2.5}}+\frac{2 B E c \operatorname{Pr} \alpha^{4} A_{2}}{45 A_{3}(1-\phi)^{2.5}}+\frac{B^{2} E c \operatorname{Pr} \alpha \operatorname{Re} A_{1} A_{2}}{45 A_{3}}+\frac{B E c \operatorname{Pr} \operatorname{Re} \alpha^{3} A_{1} A_{2}}{45 A_{3}}\right) \eta^{6} \\
& +\left(\begin{array}{l}
\frac{B^{2} E c \operatorname{Pr} \alpha^{4} A_{2}}{252 A_{3}(1-\phi)^{2.5}}+\frac{B^{2} E c \operatorname{Pr} \alpha \operatorname{Re} A_{1} A_{2}}{560 A_{3}}-\frac{B^{2} E c \operatorname{Pr} \alpha^{3} \operatorname{Re} A_{1} A_{2}}{1260 A_{3}} \\
-\frac{(1-\phi)^{2.5} B^{2} E c \operatorname{Pr} \alpha^{2} \operatorname{Re}^{2} A_{1}^{2} A_{2}}{504 A_{3}}
\end{array}\right) \eta^{8}+\ldots
\end{aligned}
$$

In a similar manner, other iterations for the solution can also be obtained.

\section{Solution Using VPM}

To solve Eqs.(9) and (10) with the associated boundary conditions (11) using VPM [40-45] the velocity and temperature can be written as,

$$
\begin{aligned}
F_{n+1}(\eta)= & B_{1}+B_{2} \eta+B_{3} \frac{\eta^{2}}{2} \\
& -\int_{0}^{\eta}\left(\frac{\eta^{2}}{2 !}-\eta s+\frac{s^{2}}{2 !}\right)\left((1-\phi)^{2.5} A_{1} 2 \alpha \operatorname{Re} F_{n}(s) F_{n}^{\prime}(s)+4 \alpha^{2} F_{n}(s)\right) d s, \\
\beta_{n+1}(\eta)= & C_{1}+C_{2} \eta \\
& -\int_{0}^{\eta}(\eta-s)\left(\frac{A_{2} E c \operatorname{Pr}}{A_{3}(1-\phi)^{2.5}}\left[4 \alpha^{2} F_{n}^{2^{\prime}}(s)+\left(F_{n^{\prime}}(s)\right)^{2}\right]\right) d s,
\end{aligned}
$$


Consuming boundary conditions, we can write Eq. (14) as

$$
\begin{aligned}
& F_{n+1}(\eta)=1+B \frac{\eta^{2}}{2}-\int_{0}^{\eta}\left(\frac{\eta^{2}}{2 !}-\eta s+\frac{s^{2}}{2 !}\right)\left((1-\phi)^{2.5} A_{1} 2 \alpha \operatorname{Re} F_{n}(s) F_{n}^{\prime}(s)+4 \alpha^{2} F_{n}(s)\right) d s, \\
& \beta_{n+1}(\eta)=C-\int_{0}^{\eta}(\eta-s)\left(\frac{A_{2} E c \operatorname{Pr}}{A_{3}(1-\phi)^{2.5}}\left[4 \alpha^{2} F_{n}^{2^{\prime}}(s)+\left(F_{n}^{\prime}(s)\right)^{2}\right]\right) d s,
\end{aligned}
$$

where $\mathrm{B}$ and $\mathrm{C}$ are the constants to be determined later by using the slip boundary conditions for velocity and temperature profiles.

First few terms of the solution are given as

$$
\begin{aligned}
& F_{0}(\eta)=1+B \frac{\eta^{2}}{2}, \\
& F_{1}(\eta)=1+B \frac{\eta^{2}}{2}-\frac{B^{2} \alpha \operatorname{Re} A_{1}(1-\phi)^{2.5} \eta^{6}}{20}-\left(B \frac{\alpha^{2}}{6}+B \frac{\operatorname{Re} \alpha A_{1}(1-\phi)^{2.5}}{12}\right) \eta^{4} \\
& F_{2}(\eta)=1+B \frac{\eta^{2}}{2}-\left(B \frac{\alpha^{2}}{6}+B \frac{\operatorname{Re} \alpha A_{1}(1-\phi)^{2.5}}{12}\right) \eta^{4} \\
& +\left(B \frac{\alpha^{4}}{45}-\frac{B^{2} \alpha \operatorname{Re} A_{1}(1-\phi)^{2.5}}{120}+\frac{B \alpha^{3} \operatorname{Re} A_{1}(1-\phi)^{2.5}}{45}+\frac{B \alpha^{3} \operatorname{Re}^{2} A_{1}^{2}\left((1-\phi)^{2.5}\right)^{2}}{1080}\right) \eta^{6} \\
& +\left(\frac{B^{2} \alpha^{3} \operatorname{Re} A_{1}(1-\phi)^{2.5}}{180}+\frac{B^{2} \alpha^{2} \operatorname{Re}^{2} A_{1}^{2}(1-\phi)^{2.5}}{560}\right) \eta^{8}+\ldots
\end{aligned}
$$

First few terms for the solution of $\beta(\eta)$ shall be of the form

$$
\begin{aligned}
\beta_{0}(\eta)= & C, \\
\beta_{1}(\eta)= & C-\frac{2 E c \operatorname{Pr} \alpha^{2} A_{2}}{A_{3}(1-\phi)^{2.5}} \eta^{2}-\frac{B^{2} E c \operatorname{Pr} \alpha^{2} A_{2}}{30 A_{3}(1-\phi)^{2.5}} \eta^{4}-\left(\frac{B^{2} E c \operatorname{Pr} A_{2}}{12 A_{3}(1-\phi)^{2.5}}+\frac{B E c \operatorname{Pr} \alpha^{2} A_{2}}{3 A_{3}(1-\phi)^{2.5}}\right) \eta^{6}, \\
\beta_{2}(\eta)= & C-\frac{2 E c \operatorname{Pr} \alpha^{2} A_{2}}{A_{3}(1-\phi)^{2.5}} \eta^{2}-\frac{B^{2} E c \operatorname{Pr} \alpha^{2} A_{2}}{30 A_{3}(1-\phi)^{2.5}} \eta^{4}+\left(\frac{B^{2} E c \operatorname{Pr} \alpha^{2} A_{2}}{90 A_{3}(1-\phi)^{2.5}}\right. \\
& \left.+\frac{2 B E c \operatorname{Pr} \alpha^{4} A_{2}}{45 A_{3}(1-\phi)^{2.5}}+\frac{B^{2} E c \operatorname{Pr} \alpha \operatorname{Re} A_{1} A_{2}}{45 A_{3}}+\frac{B E c \operatorname{Pr} \operatorname{Re} \alpha^{3} A_{1} A_{2}}{45 A_{3}}\right) \eta^{6} \\
& +\left(\begin{array}{l}
\frac{B^{2} E c \operatorname{Pr} \alpha^{4} A_{2}}{252 A_{3}(1-\phi)^{2.5}}+\frac{B^{2} E c \operatorname{Pr} \alpha \operatorname{Re} A_{1} A_{2}}{560 A_{3}}-\frac{B^{2} E c \operatorname{Pr} \alpha^{3} \operatorname{Re} A_{1} A_{2}}{1260 A_{3}} \\
-\frac{(1-\phi)^{2.5} B^{2} E c \operatorname{Pr} \alpha^{2} \operatorname{Re} A_{1}^{2} A_{2}}{504 A_{3}}
\end{array}\right) \eta^{8}+\ldots
\end{aligned}
$$

In a similar manner, other iterations for the solution can also be obtained. 
Table 1 Thermo-physical properties of water, kerosene and copper nanoparticles $[7,48]$

\begin{tabular}{llll}
\hline & $\rho\left(\mathrm{kg} / \mathrm{m}^{3}\right)$ & $C_{p}(\mathrm{~J} / \mathrm{kgK})$ & $k(W / m K)$ \\
\hline Pure water & 997.1 & 4179 & 0.613 \\
Copper $(\mathrm{Cu})$ & 8933 & 385 & 401 \\
Silver $(\mathrm{Ag})$ & 10,500 & 235 & 429 \\
\hline
\end{tabular}

\section{Results and Discussions}

Influences of different emerging parameters on the velocity and temperature profile are discussed in this section. Two subsections are used to analyze the flow behavior under varying parameters. One is dedicated for the diverging channel while the other is for the converging channel. The thermo-physical properties of base fluid and nanoparticles are given in Table 1 .

\section{Diverging Channel}

Physical behavior of the flow under varying angle $\alpha$ in the case of diverging channel is shown in Fig. 1. It can be seen that for an increase in opening angle $\alpha$, a decline in velocity is observed. Maximum of the velocity is seen near the centerline, while in vicinity of the walls lower values of the velocity are observed. Velocity for Ag-Water nanofluid is slightly lower as compared to the velocity for $\mathrm{Cu}$-Water. This is because of the higher values of Ag density. Figure 2 depicts the outcomes of increasing Reynolds number. Increasing values of Re tend to decelerate the flow considerably. A more curvy profile at the centerline of the channel can be observed. It can also be seen that forincreasing Re, backflow regions emerge that may lead to the separation near the walls.

Figure 3 demonstrates the behavior of nanoparticle volume fraction $\phi$ on the flow in a diverging channel. It is evident, with an increase in the volume fraction of nanoparticles near the walls, a considerable change in the velocity can be seen, while there is almost a negligible effect at the centerline of the channel. Again, lower values of velocity are observed for AgWater case, it may be caused due to the increasing values of density that makes the nanoparticle to affect more. The velocity slip parameter increases the velocity quite rapidly as shown in Fig. 4. Since, the slip velocity condition is taken along the walls, therefore, no effect on the velocity is seen at the centerline of the channel.

Fig. 1 Variation of $F(\eta)$ for different values of $\alpha$ for diverging channel

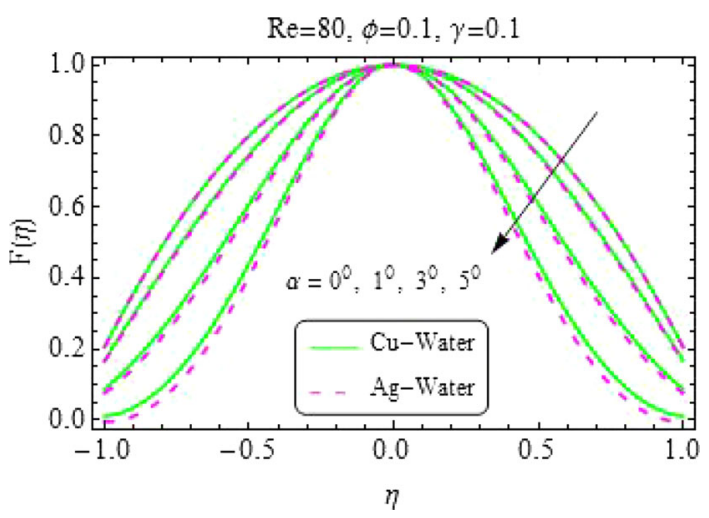


Fig. 2 Variation of $F(\eta)$ for different values of Re for diverging channel

Fig. 3 Variation of $F(\eta)$ for different values of $\varphi$ for diverging channel

Fig. 4 Variation of $F(\eta)$ for different values of $\gamma$ for diverging channel
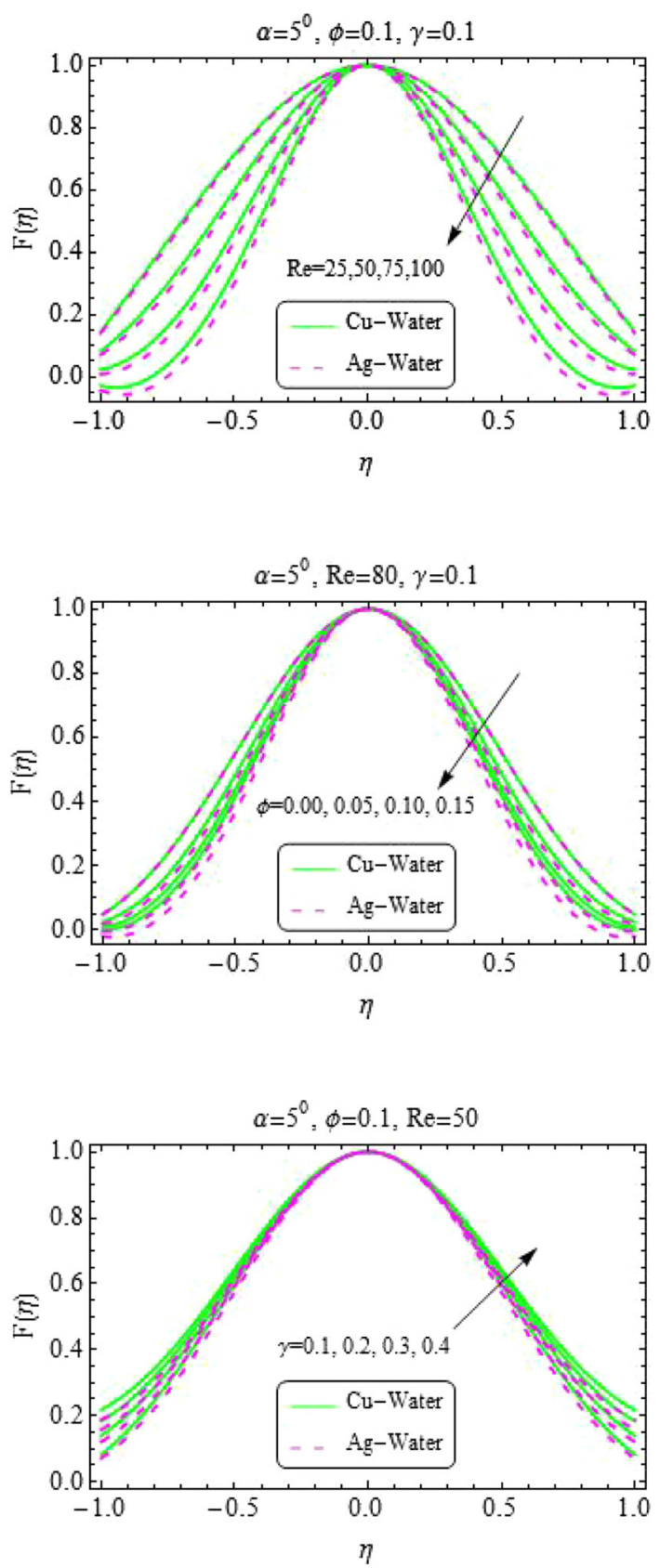

To discuss the influence of $\alpha, \operatorname{Re}, \mathrm{Ec}, \delta$ and $\gamma$ on the temperature profile for the case of diverging channel, Figs. 5, 6, 7, 8, 9 and 10 are plotted. Since we are taking water as a base fluid, therefore, the value of Prandtl number Pr is fixed as 6.2. Fig. 5 is sketched to see the effects of increasing angle $\alpha$. With an increase in the gap between the walls, temperature of the fluid is seen to be getting higher. This increase is prominent at the centerline of the 
Fig. 5 Variation of $\beta(\eta)$ for different values of $\alpha$ for diverging channel
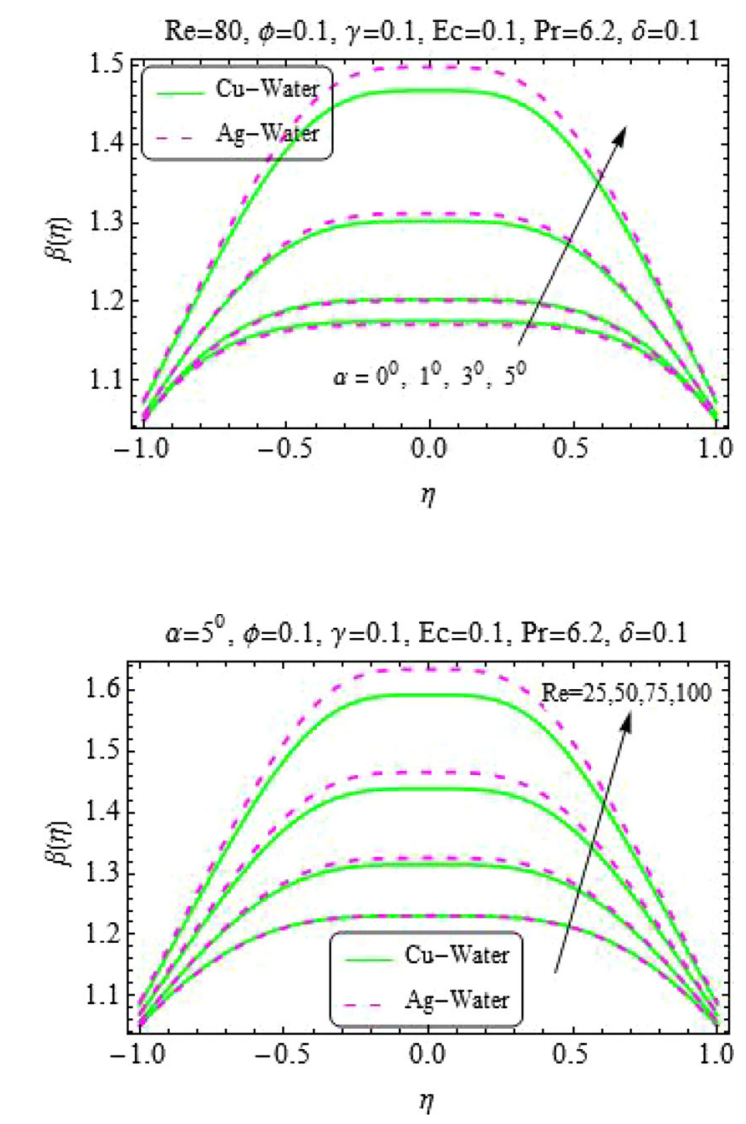

Fig. 6 Variation of $\beta(\eta)$ for different values of Re for diverging channel

channel. Also, the temperature is seen to be on the higher side for silver nanoparticles as compared to the copper nanoparticles. Higher value of thermal conductivity of silver is a major cause for this increment in temperature. Almost identical behavior of the temperature profile is observed in Fig. 6 for rising Re. The only difference is that,the temperature is slightly on the higher side for increasing Re. It means that the increase in viscous forces is also responsible for an increase in the temperature.

Figure 7 explains the variations of temperature with increasing nanoparticle volume fraction. A definite rise in temperature is seen. Again, the temperature for silver nanoparticles is on the higher side. This explains the influence of higher thermal conductivity and specific heat. Also, copper nanoparticles are much more efficient to control the rise in temperature for various practical situations as compared to silver nanoparticles. Here, the temperature exhibits lower values for $\mathrm{Cu}$ nanoparticles as compared to $\mathrm{Ag}$.

Figures 7 and 8 illustrate the influence of different values oftemperature slip parameter and Eckert number Ec on the temperature profile. From Fig. 7, it can easily be seen that the temperature slip parameter affects the temperature profile starting near the walls continuing towards the centerline of the channel. $\mathrm{Cu}$ nano-fluid have slightly lower temperature as we move towards the center of the channel compared to Ag nano-fluid. Eckert number describes the effects due to the dissipation term in energy equation. Increase in viscous forces causes the dissipation to affect temperature profile more promptly. Due to higher thermal conductivity 
Fig. 7 Variation of $\beta(\eta)$ for different values of $\phi$ for diverging channel

Fig. 8 Variation of $\beta(\eta)$ for different values of $\gamma$ for diverging channel

Fig. 9 Variation of $\beta(\eta)$ for different values of $\delta$ for diverging channel
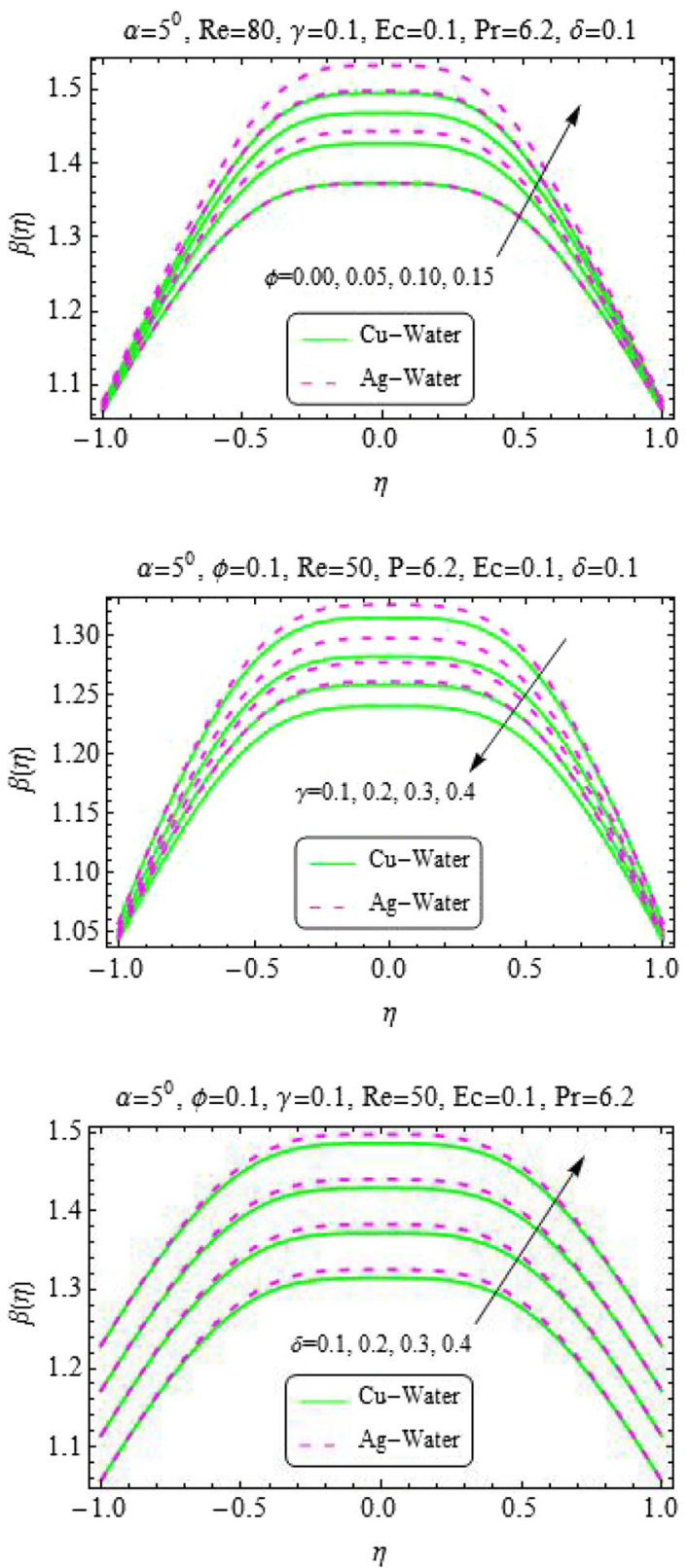

and specific heat, $\mathrm{Ag}$ nanoparticles affect the flow more at the center as compared to $\mathrm{Cu}$ nanoparticles.

\section{Converging Channel}

Behavior of the flow for changing $\alpha$ and Re in converging channel is quite opposite to the one seen in diverging channel as depicted in Figs. 11 and 12. At the center of the channel, velocity 
Fig. 10 Variation of $\beta(\eta)$ for different values of $E c$ for diverging channel

Fig. 11 Variation of $F(\eta)$ for different values of $\alpha$ for converging channel

Fig. 12 Variation of $F(\eta)$ for different values of $\mathrm{Re}$ for converging channel
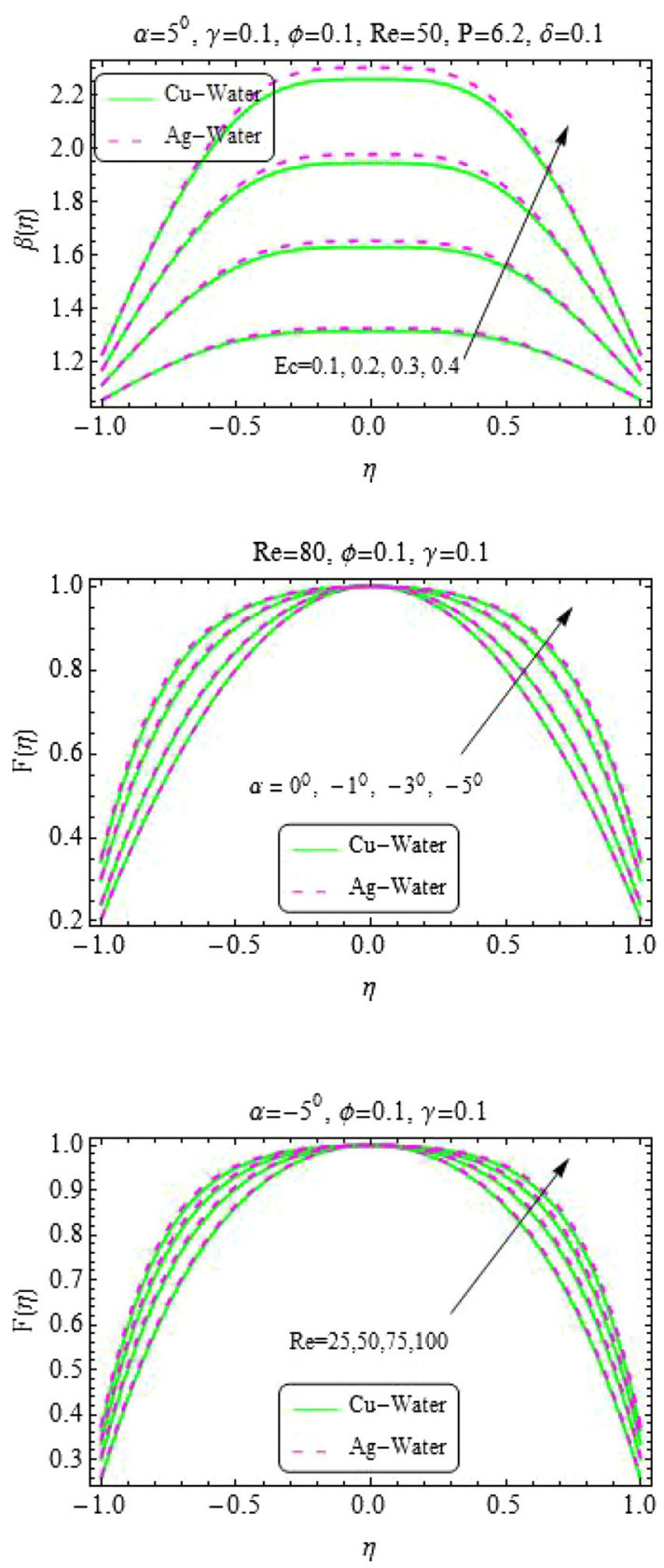

seems to be constantand a steep decrease is seen near the walls of the channel that clearly exhibits the boundary layer character. Nanoparticle volume fraction increases the velocity for the case of converging channel. Figure 13 is plotted to verify this fact. For velocity slip parameter $\gamma$, velocity profile behaves in a similar manner as we see for the case of diverging channel, i.e. an increase in velocity is observed (see Fig. 14). 
Fig. 13 Variation of $F(\eta)$ for different values of $\phi$ for converging channel

Fig. 14 Variation of $F(\eta)$ for different values $\gamma$ for converging channel

Fig. 15 Variation of $\beta(\eta)$ for different values of $\alpha$ for converging channel
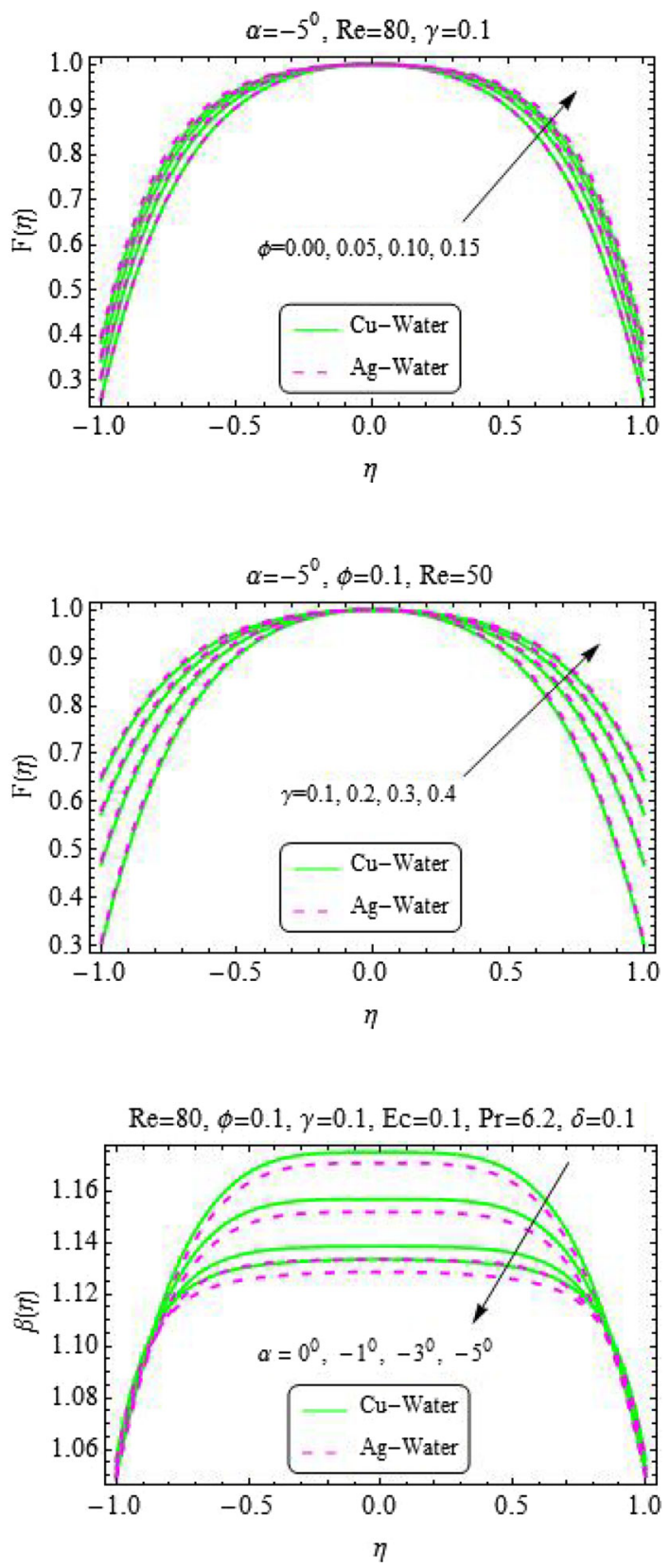

Effects of angle $\alpha$, Reynolds number Re, nanoparticle volume fraction $\phi$, velocity slip parameter $\gamma$, thermal slip parameter $\delta$ and Eckert number Ec on the temperature profile for converging channel are presented in Figs. 15, 16, 17, 18, 19 and 20, respectively. It is clear that $\beta(\eta)$ decreases with an increase in $\alpha, \operatorname{Re}$ and $\phi$. That is quite opposite as compared to diverging channel. For velocity slip parameter $\gamma$, both the profiles are almost identical. Here, $\mathrm{Cu}$ and $\mathrm{Ag}$ nanoparticles have a slight difference in temperature and velocity 
Fig. 16 Variation of $\beta(\eta)$ for different values of Re for converging channel

Fig. 17 Variation of $\beta(\eta)$ for different values of $\phi$ for converging channel

Fig. 18 Variation of $\beta(\eta)$ for different values of $\gamma$ converging channel
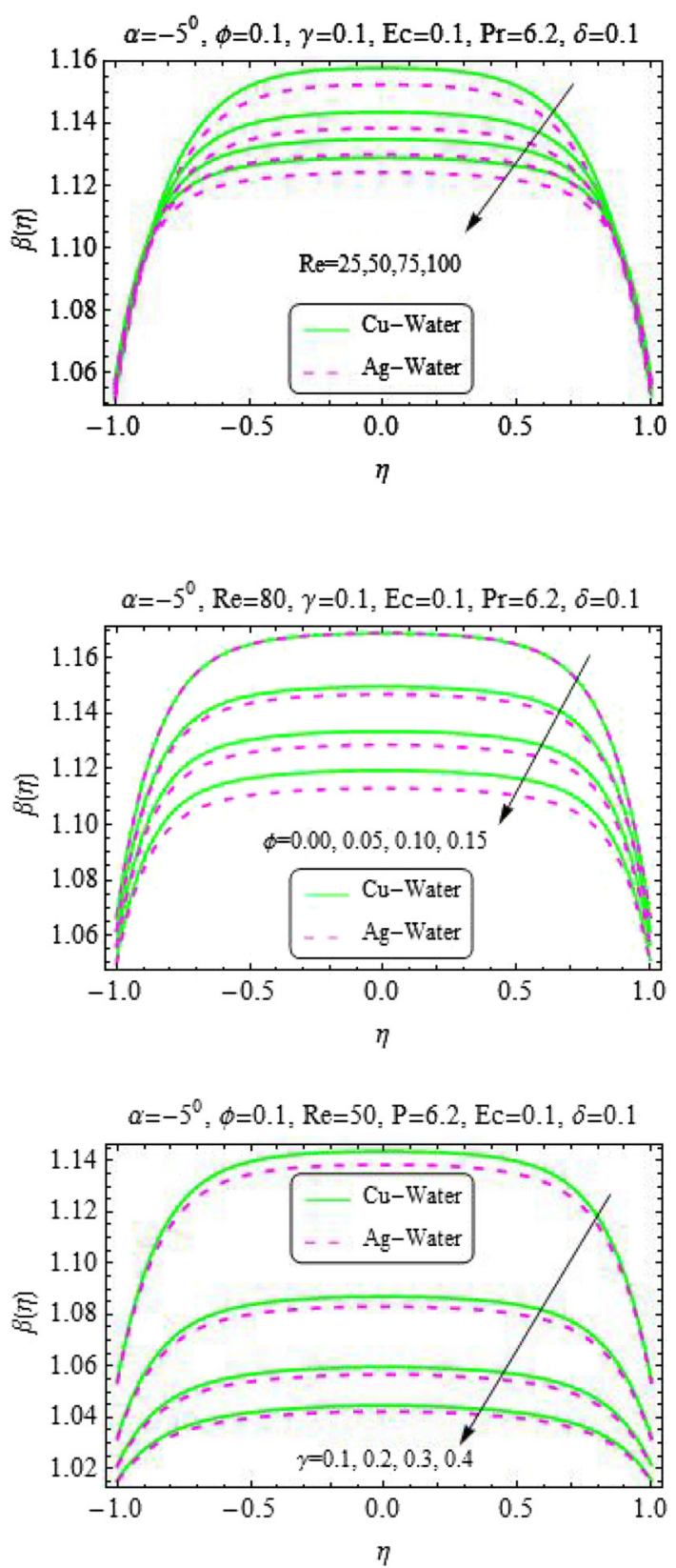

that is same as for the case of diverging channel. $\delta$ and Ec affect the temperature in a similar manner for converging channel and anincrease in temperature is observed. Further $\beta(\eta)$ possess its maximum value near the locality of center of the channel for all these parameters.

It is important to show that the series solutions given in Eqs. (13)-(15) are convergent. Tables 2 and 3 are drawn to discuss the convergence of the solution obtained for both 
Fig. 19 Variation of $\beta(\eta)$ for different values of $\delta$ converging channel

Fig. 20 Variation of $\beta(\eta)$ for different values of $E c$ converging channel
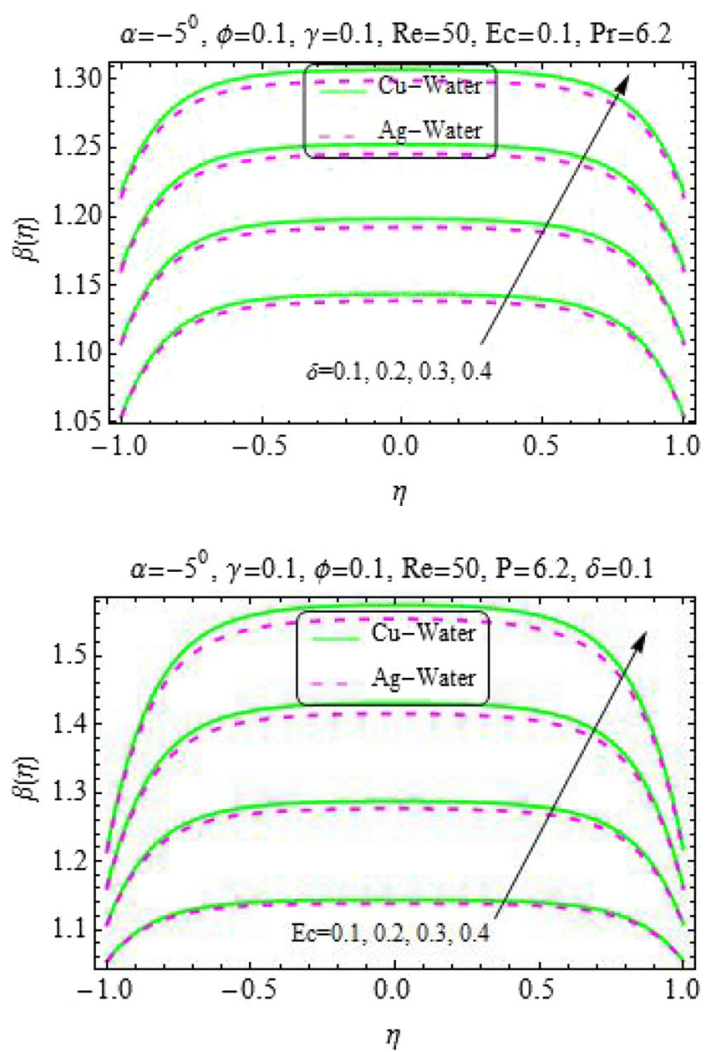

Table 2 Convergence of velocity and temperature proflies for $\mathrm{Cu}$-Water with $\mathrm{Pr}=6.2, \mathrm{Ec}=0.1, \mathrm{Re}=50$ and $\phi=\gamma=\delta=0.1$

\begin{tabular}{|c|c|c|c|c|c|c|c|c|}
\hline \multirow[t]{3}{*}{ Appox } & \multicolumn{4}{|l|}{ VPM } & \multicolumn{4}{|l|}{ VIM } \\
\hline & \multicolumn{2}{|c|}{$\begin{array}{l}\text { Diverging channel } \\
\left(\alpha=5^{\circ}\right)\end{array}$} & \multicolumn{2}{|c|}{$\begin{array}{l}\text { Converging chan- } \\
\text { nel }\left(\alpha=-5^{\circ}\right)\end{array}$} & \multicolumn{2}{|c|}{$\begin{array}{l}\text { Diverging channel } \\
\left(\alpha=5^{\circ}\right)\end{array}$} & \multicolumn{2}{|c|}{$\begin{array}{l}\text { Converging chan- } \\
\text { nel }\left(\alpha=-5^{\circ}\right)\end{array}$} \\
\hline & $-F^{\prime \prime}(0)$ & $\beta(0)$ & $-F^{\prime \prime}(0)$ & $\beta(0)$ & $-F^{\prime \prime}(0)$ & $\beta(0)$ & $-F^{\prime \prime}(0)$ & $\beta(0)$ \\
\hline 1 & 3.012650 & 1.637065 & 4.408351 & 1.323688 & 3.012650 & 1.637065 & 4.408351 & 1.323688 \\
\hline 2 & 3.960242 & 1.248393 & 4.204042 & 1.252284 & 3.960242 & 1.248393 & 4.204042 & 1.252284 \\
\hline 3 & 4.075306 & 1.323792 & 4.384589 & 1.336537 & 4.075306 & 1.323792 & 4.384589 & 1.336537 \\
\hline 4 & 4.067243 & 1.314298 & 4.374261 & 1.336547 & 4.067243 & 1.314298 & 4.374261 & 1.336547 \\
\hline 5 & 4.067678 & 1.314870 & 4.374850 & 1.325150 & 4.067678 & 1.314870 & 4.374850 & 1.325150 \\
\hline 6 & 4.067661 & 1.314845 & 4.374827 & 1.325862 & 4.067667 & 1.314849 & 4.374838 & 1.325862 \\
\hline 7 & 4.067662 & 1.314845 & 4.374828 & 1.325829 & 4.067663 & 1.314844 & 4.374830 & 1.325836 \\
\hline 8 & 4.067662 & 1.314845 & 4.374828 & 1.325830 & 4.067662 & 1.314845 & 4.374828 & 1.325830 \\
\hline 10 & 4.067662 & 1.314845 & 4.374828 & 1.325830 & 4.067662 & 1.314845 & 4.374828 & 1.325830 \\
\hline 12 & 4.067662 & 1.314845 & 4.374828 & 1.325830 & 4.067662 & 1.314845 & 4.374828 & 1.325830 \\
\hline 15 & 4.067662 & 1.314845 & 4.374828 & 1.325830 & 4.067662 & 1.314845 & 4.374828 & 1.325830 \\
\hline Numerical & 4.067662 & 1.314845 & 4.384589 & 1.325830 & 4.067662 & 1.314845 & 4.384589 & 1.325830 \\
\hline
\end{tabular}


Table 3 Convergence of velocity and temperature proflies for Ag-Water with $\operatorname{Pr}=6.2, \mathrm{Ec}=0.1, \operatorname{Re}=50$ and $\phi=\gamma=\delta=0.1$

\begin{tabular}{|c|c|c|c|c|c|c|c|c|}
\hline \multirow[t]{3}{*}{ Appox } & \multicolumn{4}{|l|}{ VPM } & \multicolumn{4}{|l|}{ VIM } \\
\hline & \multicolumn{2}{|c|}{$\begin{array}{l}\text { Diverging channel } \\
\left(\alpha=5^{\circ}\right)\end{array}$} & \multicolumn{2}{|c|}{$\begin{array}{l}\text { Converging chan- } \\
\text { nel }\left(\alpha=-5^{\circ}\right)\end{array}$} & \multicolumn{2}{|c|}{$\begin{array}{l}\text { Diverging channel } \\
\left(\alpha=5^{\circ}\right)\end{array}$} & \multicolumn{2}{|c|}{$\begin{array}{l}\text { Converging chan- } \\
\text { nel }\left(\alpha=-5^{\circ}\right)\end{array}$} \\
\hline & $-F^{\prime \prime}(0)$ & $\beta(0)$ & $-F^{\prime \prime}(0)$ & $\beta(0)$ & $-F^{\prime \prime}(0)$ & $\beta(0)$ & $-F^{\prime \prime}(0)$ & $\beta(0)$ \\
\hline 1 & 0.755462 & 1.049059 & 0.720485 & 1.044450 & 0.755462 & 1.049059 & 0.720485 & 1.044450 \\
\hline 2 & 0.628904 & 1.110605 & 0.585231 & 1.102826 & 0.628904 & 1.110605 & 0.585231 & 1.102826 \\
\hline 3 & 0.609627 & 1.137902 & 0.563226 & 1.131637 & 0.609627 & 1.137902 & 0.563226 & 1.131637 \\
\hline 4 & 0.607486 & 1.142997 & 0.560567 & 1.137630 & 0.607486 & 1.142997 & 0.560567 & 1.137630 \\
\hline 5 & 0.607318 & 1.143550 & 0.560338 & 1.138406 & 0.607318 & 1.143550 & 0.560338 & 1.138418 \\
\hline 6 & 0.607308 & 1.143590 & 0.560323 & 1.138409 & 0.607310 & 1.143583 & 0.560327 & 1.138411 \\
\hline 7 & 0.607307 & 1.143593 & 0.560323 & 1.138409 & 0.607308 & 1.143590 & 0.560324 & 1.138409 \\
\hline 8 & 0.607307 & 1.143593 & 0.560323 & 1.138409 & 0.607307 & 1.143593 & 0.560323 & 1.138409 \\
\hline 10 & 0.607307 & 1.143593 & 0.560323 & 1.138409 & 0.607307 & 1.143593 & 0.560323 & 1.138409 \\
\hline 12 & 0.607307 & 1.143593 & 0.560323 & 1.138409 & 0.607307 & 1.143593 & 0.560323 & 1.138409 \\
\hline 15 & 0.607307 & 1.143593 & 0.560323 & 1.138409 & 0.607307 & 1.143593 & 0.560323 & 1.138409 \\
\hline Numerical & 0.607307 & 1.143593 & 0.560323 & 1.138409 & 0.607307 & 1.143593 & 0.560323 & 1.138409 \\
\hline
\end{tabular}

Table 4 Comparison of present results to the already existing solutions in literature for $\phi=\gamma=\delta=0$

\begin{tabular}{|c|c|c|c|c|c|c|c|c|c|}
\hline \multirow[t]{2}{*}{$\operatorname{Re} \downarrow$} & \multicolumn{4}{|c|}{$-F^{\prime \prime}(0)\left(\alpha=5^{\circ}\right)$} & \multirow[t]{2}{*}{$\operatorname{Re} \downarrow$} & \multicolumn{4}{|c|}{$-F^{\prime \prime}(0)\left(\alpha=-5^{\circ}\right)$} \\
\hline & VPM & VIM & RK-4 & [46] & & VPM & VIM & RK-4 & [47] \\
\hline 20 & 2.527192 & 2.527192 & 2.527192 & 2.527192 & 10 & 1.784547 & 1.784547 & 1.784547 & 1.784547 \\
\hline 60 & 3.942140 & 3.942140 & 3.942140 & 3.942140 & 30 & 1.413692 & 1.413692 & 1.413692 & 1.413692 \\
\hline 100 & 5.869165 & 5.869165 & 5.869165 & 5.869165 & 50 & 1.121989 & 1.121989 & 1.121989 & 1.121989 \\
\hline 140 & 8.207326 & 8.207326 & 8.207326 & 8.207326 & 70 & 0.893474 & 0.893474 & 0.893474 & 0.893474 \\
\hline 180 & 10.79207 & 10.79207 & 10.79207 & 10.79207 & 100 & 0.640178 & 0.640178 & 0.640178 & 0.640178 \\
\hline
\end{tabular}

diverging and converging channels. It can be seen only eight iterations are enough for a convergent solution for both velocity and temperature profiles for $\mathrm{Cu}$ and $\mathrm{Ag}$ water nanofluids for the case of VPM, however VIM requires some more iterations to give convergent results. Table 4 gives a comparison of our computed results to the already existing solutions obtained by Mosta et al [42,43]. An excellent agreement is seen between the solutions.

Same problem is solved by using a well-known numerical method, i.e. Runge-Kutta method (RK-4). To validate our results, comparisons of VPM and VIM solutions to the numerical solutions for temperature distributions for both diverging and converging channels is presented in Tables 5 and 6 . This shows the efficiency and simplicity of the solution obtained by VPM and VIMand proves that without doing much computation and hard work we can still attain an accurate solution very easily.

The influence of $\alpha, \operatorname{Re}, \phi$ and slip parameter $\gamma$ on skin friction coefficient $C_{F}$ for diverging and converging channel for both $\mathrm{Cu}$ and $\mathrm{Ag}$ is shown in Table 7. It is evident that for a diverging channel $C_{F}$ decreases with an increase in $\alpha$, Re, $\phi$ and $\gamma$. In case of convergent channel, 
Table 5 Comparison of numericalVPM and VIM solutions for $\mathrm{Cu}$-Water with $\operatorname{Pr}=6.2, \mathrm{Ec}=0.1, \mathrm{Re}=50$ and $\phi=\gamma=\delta=0.1$

\begin{tabular}{|c|c|c|c|c|c|c|}
\hline \multirow[t]{4}{*}{$\eta$} & \multicolumn{6}{|l|}{$\mathrm{Cu}$-water } \\
\hline & \multicolumn{3}{|c|}{ Diverging channel $\left(\alpha=5^{\circ}\right)$} & \multicolumn{3}{|c|}{ Converging channel $\left(\alpha=-5^{\circ}\right)$} \\
\hline & \multicolumn{3}{|l|}{$\beta(\eta)$} & \multirow[b]{2}{*}{ VPM } & \multirow[b]{2}{*}{ VIM } & \multirow[b]{2}{*}{ RK-4 } \\
\hline & VPM & VIM & RK-4 & & & \\
\hline 0.1 & 1.314675 & 1.314675 & 1.314675 & 1.143500 & 1.143500 & 1.143500 \\
\hline 0.2 & 1.31326 & 1.31326 & 1.31326 & 1.143200 & 1.143200 & 1.143200 \\
\hline 0.3 & 1.308296 & 1.308296 & 1.308296 & 1.142613 & 1.142613 & 1.142613 \\
\hline 0.4 & 1.297051 & 1.297051 & 1.297051 & 1.141561 & 1.141561 & 1.141561 \\
\hline 0.5 & 1.277381 & 1.277381 & 1.277381 & 1.139684 & 1.139684 & 1.139684 \\
\hline 0.6 & 1.248351 & 1.248351 & 1.248351 & 1.136262 & 1.136262 & 1.136262 \\
\hline 0.7 & 1.210306 & 1.210306 & 1.210306 & 1.129902 & 1.129902 & 1.129902 \\
\hline 0.8 & 1.164553 & 1.164553 & 1.164553 & 1.117968 & 1.117968 & 1.117968 \\
\hline 0.9 & 1.112888 & 1.112888 & 1.112888 & 1.095642 & 1.095642 & 1.095642 \\
\hline 1.0 & 1.057170 & 1.057170 & 1.057170 & 1.054530 & 1.054530 & 1.054530 \\
\hline
\end{tabular}

Table 6 Comparison of numerical VPM and VIM solutions for $\mathrm{Cu}$-Water with $\operatorname{Pr}=6.2, \mathrm{Ec}=0.1, \mathrm{Re}=50$ and $\phi=\gamma=\delta=0.1$

\begin{tabular}{|c|c|c|c|c|c|c|}
\hline \multirow[t]{4}{*}{$\eta$} & \multicolumn{6}{|l|}{ Ag-water } \\
\hline & \multicolumn{3}{|c|}{ Diverging channel $\left(\alpha=5^{\circ}\right)$} & \multicolumn{3}{|c|}{ Converging channel $\left(\alpha=-5^{\circ}\right)$} \\
\hline & \multicolumn{3}{|l|}{$\beta(\eta)$} & \multirow[b]{2}{*}{ VPM } & \multirow[b]{2}{*}{ VIM } & \multirow[b]{2}{*}{ RK-4 } \\
\hline & VPM & VIM & RK-4 & & & \\
\hline 0.1 & 1.325651 & 1.325651 & 1.325651 & 1.138319 & 1.138319 & 1.138319 \\
\hline 0.2 & 1.324102 & 1.324102 & 1.324102 & 1.138030 & 1.138030 & 1.138030 \\
\hline 0.3 & 1.318630 & 1.318630 & 1.318630 & 1.137475 & 1.137475 & 1.137475 \\
\hline 0.4 & 1.306316 & 1.306316 & 1.306316 & 1.136501 & 1.136501 & 1.136501 \\
\hline 0.5 & 1.285009 & 1.285009 & 1.285009 & 1.134785 & 1.134785 & 1.134785 \\
\hline 0.6 & 1.253986 & 1.253986 & 1.253986 & 1.131670 & 1.131670 & 1.131670 \\
\hline 0.7 & 1.213924 & 1.213924 & 1.213924 & 1.125841 & 1.125841 & 1.125841 \\
\hline 0.8 & 1.166456 & 1.166456 & 1.166456 & 1.114732 & 1.114732 & 1.114732 \\
\hline 0.9 & 1.113616 & 1.113616 & 1.113616 & 1.093518 & 1.093518 & 1.093518 \\
\hline 1.0 & 1.057371 & 1.057371 & 1.057371 & 1.053556 & 1.053556 & 1.053556 \\
\hline
\end{tabular}

$C_{F}$ increases with an increase in $\alpha$ and Re but for increasing $\gamma$ there is a decrement in $C_{F}$. For Ag water case most of these values are on the higher side. Table 8 gives us numerical values for Nusselt number. Magnitude of Nusselt numbers is seen to be increasing function of $\operatorname{Re}, \alpha$, and temperature slip parameter for both diverging and converging channels while decreasing function for $\phi$ and $\gamma$ for both the channels. Here, for $\mathrm{Cu}$ Water case, these values are on the higher side as compared to Ag-water. 
Table 7 Numerical values of skin friction coefficient for different values of parameters for diverging channel and converging channel

\begin{tabular}{|c|c|c|c|c|c|c|c|c|}
\hline \multirow[t]{2}{*}{$R e$} & \multirow[t]{2}{*}{$\alpha$} & \multirow[t]{2}{*}{$\phi$} & \multirow[t]{2}{*}{$\gamma$} & \multicolumn{2}{|c|}{$-\operatorname{Re}_{r} C_{F}$ (Diverging channel) } & \multirow[b]{2}{*}{$\alpha$} & \multicolumn{2}{|c|}{$-\operatorname{Re}_{r} C_{F}$ (Converging channel) } \\
\hline & & & & (Cu-water) & (Ag-water) & & (Cu-water) & (Ag-water) \\
\hline 30 & \multirow[t]{3}{*}{$5^{\circ}$} & \multirow[t]{5}{*}{0.1} & \multirow[t]{8}{*}{0.1} & 1.415299 & 1.461898 & \multirow[t]{3}{*}{$-5^{\circ}$} & 2.83034 & 3.135548 \\
\hline 60 & & & & 0.609661 & 0.577071 & & 3.351252 & 3.770734 \\
\hline 90 & & & & -0.099886 & -0.283066 & & 3.767534 & 4.199945 \\
\hline \multirow[t]{8}{*}{50} & $1^{\circ}$ & & & 1.949780 & 2.240549 & $-1^{\circ}$ & 2.420549 & 2.653535 \\
\hline & $3^{\circ}$ & & & 1.418840 & 2.835085 & $-3^{\circ}$ & 3.191413 & 3.137832 \\
\hline & \multirow[t]{6}{*}{$5^{\circ}$} & 0.04 & & 1.088018 & 1.171115 & \multirow[t]{6}{*}{$-5^{\circ}$} & 3.200207 & 3.522161 \\
\hline & & 0.08 & & 0.932382 & 0.905231 & & 3.206916 & 3.556230 \\
\hline & & 0.12 & & 0.825845 & 0.756479 & & 3.164811 & 3.525995 \\
\hline & & \multirow[t]{3}{*}{0.1} & 0.1 & 0.873484 & 0.823169 & & 3.191413 & 3.548343 \\
\hline & & & 0.2 & 0.742656 & 0.698562 & & 2.490730 & 2.755821 \\
\hline & & & 0.3 & 0.649348 & 0.609676 & & 2.031677 & 2.240557 \\
\hline
\end{tabular}

Table 8 Numerical values for Nusselt number for different values of parameters

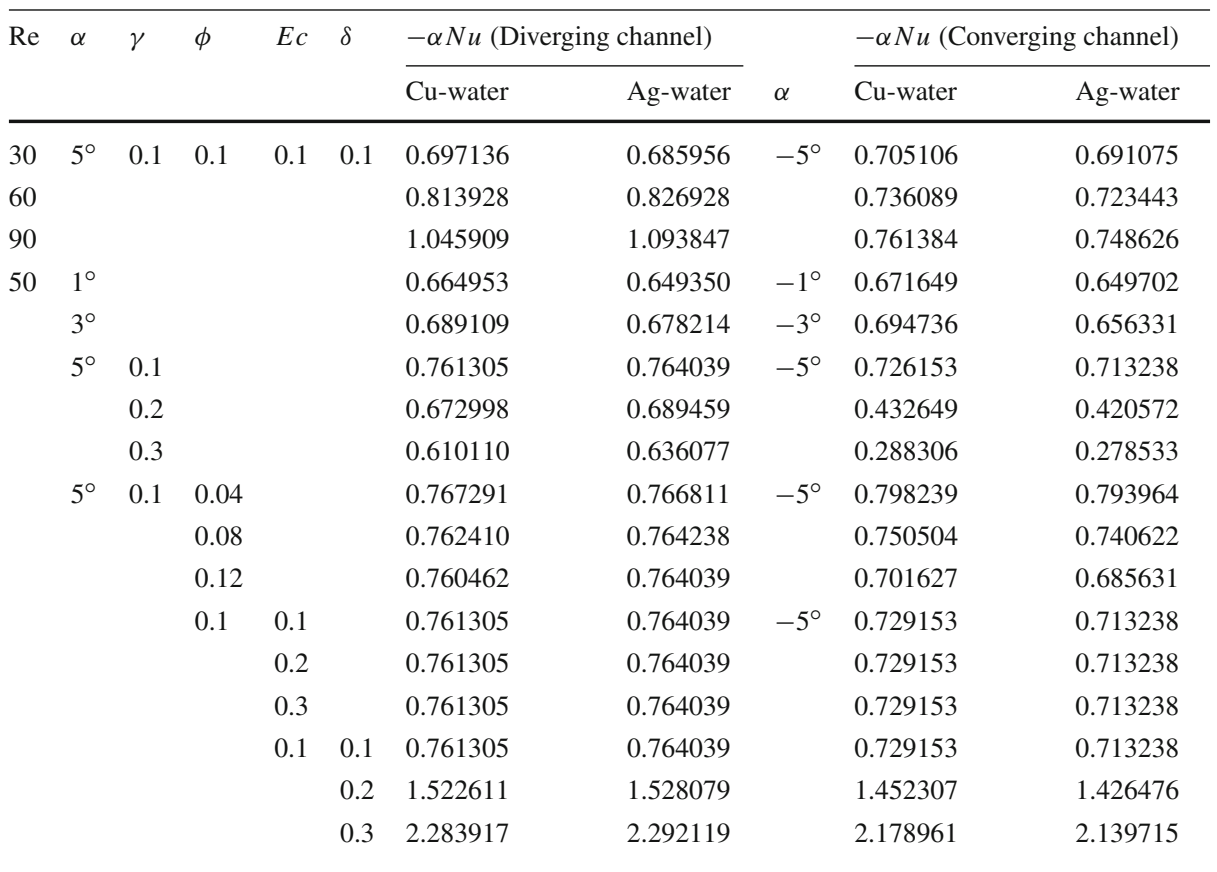

\section{Conclusions}

Analytical and numerical solutions for the flow of nanofluids in a converging and diverging channel in presence of velocity and temperature slip is presented. Copper and silver nanoparticles are used to study the problem. Graphs are plotted to analyze the flow phenomena under 
varying parameters. Solutions are obtained by using VIM, VPM and RK-4 techniques. Excellent agreement is found betweenthe solutions. Present results are also compared with some of the already existing solutions in literature and the results are found to be in great agreement. Convergence analysis is also carried out to prove that our solutions are convergent. It can be concluded from the present study that for the case of diverging channel, backflow may occur near the walls that will lead to separation for some values of parameter involved. For converging channel, the boundary layer character is seen for some parameters. The velocity and temperature of silver nano-fluid are seen to be on the higher side for diverging channel, while the phenomena is reversed for converging channel. This problem can also be studied for different type of nanofluids using some other base fluids and nanoparticles.

\section{References}

1. Choi, S.U.S.: Enhancing thermal conductivity of fluids with nanoparticle. In: Siginer, D.A., Wang, H.P. (eds.) Developments and Applications of Non-Newtonian Flows, vol. 231/ MD-vol. 66, pp. 99-105. ASME FED, New York (1995)

2. Choi, S.U.S., Zhang, Z.G., Yu, W., Lockwood, F.E., Grulke, E.A.: Anomalously thermal conductivity enhancement in nanotube suspensions. Appl. Phys. Lett. 79, 2252-2254 (2001)

3. Buongiorno, J.: Convective transport in nanofluids. ASME J. Heat Transf. 128, 240-250 (2006)

4. Nield, D.A., Kuznetsov, A.V.: The onset of convection in a horizontal nanofluid layer of finite depth: a revised model. Int. J. Heat Mass Transf. 77, 915-918 (2014)

5. Nield, D.A., Kuznetsov, A.V.: Natural convective boundary-layer flow of a nanofluid past a vertical plate: a revised model. Int. J. Therm. Sci. 77, 126-129 (2014)

6. Khan, W.A., Pop, I.: Boundary-layer flow of a nanofluid past a stretching sheet. Int. J. Heat Mass Transf. 53, 2477-2483 (2010)

7. Nadeem, S., Haq, R.U., Khan, Z.H.: Heat transfer analysis of water-based nanofluid over an exponentially stretching sheet. Alex. Eng. J. 53, 219-224 (2014)

8. Akbar, N.S., Nadeem, S., Haq, R.U., Khan, Z.H.: Radiation effects on MHD stagnation point flow of nano fluid towards a stretching surface with convective boundary condition. Chin. J. Aeronaut. 26(6), 1389-1397 (2013)

9. Nadeem, S., Haq, R.U.: Effect of thermal radiation for megnetohydrodynamic boundary layer flow of a nanofluid past a stretching sheet with convective boundary Conditions. J. Comput. Theor. Nanosci. 11, 32-40 (2013)

10. Khan, U., Ahmed, N., Khan, S.I.U., Mohyud-din, S.T.: Thermo-diffusion and MHD effects on stagnation point flow towards a stretching sheet in a nanofluid. Propuls. Power Res. 3(3), 151-158 (2014)

11. Jeffery, G.B.: The two-dimensional steady motion of a viscous fluid. Philos. Mag. 6, 455-465 (1915)

12. Hamel, G.: SpiralförmigeBewgungenZäherFlüssigkeiten. Jahresber. Deutsch. Math. Verein 25, 34-60 (1916)

13. Goldstein, S.: Modern Developments in Fluid Mechanics. Clarendon Press, Oxford (1938)

14. Rosenhead, L.: The steady two-dimensional radial flow of viscous fluid between two inclined plane walls. Proc. R. Soc. A 175, 436-467 (1940)

15. Fraenkel, L.E.: On the Jeffery-Hamel solutions for flow between plane walls. Proc. R. Soc. A 267, 119-138 (1962)

16. Batchelor, K.: An Introduction to Fluid Dynamics. Cambridge University Press, Cambridge (1967)

17. Sadri, R.: Channel entrance flow, PhD thesis, Dept. Mechanical Engineering, the University of Western Ontario (1997)

18. Hamadiche, M., Scott, J., Jeandel, D.: Temporal stability of Jeffery-Hamel flow. J. Fluid Mech. 268, 71-88 (1994)

19. Navier, C.L.M.H.: Memoire sur les lois du mouvement des fuides. Mem. Acad. Sci. Inst. de France. 1, 389-440 (1823)

20. Neto, C., Evans, D.R., Bonaccurso, E., Butt, H.J., Craig, V.S.J.: Boundary slip in Newtonian liquids: a review of experimental studies. Rep. Prog. Phys. 68, 2859-2897 (2005)

21. Ellahi, R.: Exact solutions of flows of an Oldroyd 8-constant fluid with nonlinear slip conditions. Z. Naturforsch 65a, 1081-1086 (2010)

22. Ellahi, R., Hayat, T., Mahomed, F.M.: Generalized couette flow of a third-grade fluid with slip: the exact solutions. Z. Naturforsch 65a, 1071-1076 (2010) 
23. Hussain, A., Mohyud-din, S.T., Cheema, T.A.: Analytical and numerical approaches to squezing flow and heat transfer between two parallel disks with velocity slip and temperature jump. Chin. Phys. Lett. 29, 114705 (2012)

24. Akbar, N.S., Nadeem, S.: Thermal and velocity slip effects on the peristaltic flow of a six constant Jeffrey's fluid model. Int. J. Heat Mass Transf. 55, 3964-3970 (2012)

25. Dorrepaal, J.M.: Slip flow in converging and diverging channels. J. Eng. Math. 27, 343-356 (1993)

26. Ganji, D.D., Hatami, M.: Three weighted residual methods based on Jeffery-Hamel flow. Int. J. Numer. Methods Heat Fluid Flow 24(3), 654-668 (2014)

27. Hatami, M., Ganji, D.D.: MHD nanofluid flow analysis in divergent and convergent channels using WRMs and numerical method. Int. J. Numer. Methods Heat Fluid Flow 24(5), 1191-1203 (2014)

28. Sheikholeslami, M., Ganji, D.D., Ashorynejad, H.R., Rokni, H.B.: Analytical investigation of JefferyHamel flow with high magnetic field and nanoparticle by Adomian decomposition method. Appl. Math. Mech. Engl. Ed. 33, 25-36 (2012)

29. Khan, U., Ahmed, N., Zaidi, Z.A., Asadullah, M., Mohyud-din, S.T.: Effects of velocity slip and temperature jump on Jeffery Hamel flow with heat transfer, engineering science and technology: an international journal, Accepted

30. Abbasbandy, S., Hayat, T.: Solution of the MHD Falkner-Skan flow by Hankel-Pade method. Phys. Lett. A. 373, 731-734 (2009)

31. Abbasbandy, S.: Extended Newton's method for a system of nonlinear equations by modified Adomian decomposition method. Appl. Math. Comput. 170, 648-656 (2005)

32. Asadullah, M., Khan, U., Ahmed, N., Manzoor, R., Mohyud-Din, S.T.: MHD flow of a Jeffery fluid in converging and diverging channels. Int. J. Mod. Math. Sci. 6, 92-106 (2013)

33. He, J.H., Wu, X.H.: Construction of solitary solution and compaction-like solution by variational iteration method. Chaos Solitons Fractals 29(1), 108-113 (2006)

34. Abdou, M.A., Soliman, A.A.: New applications of variational iteration method. Phys. D 211, 1-8 (2005)

35. Abbasbandy, S.: Numerical solution of non-linear Klein-Gordon equations by variational iteration method. Int. J. Numer. Methods Eng. 70(7), 876-881 (2007)

36. Noor, M.A., Mohyud-Din, S.T.: Variational iteration technique for solving higher order boundary value problems. Appl. Math. Comput. 189, 1929-1942 (2007)

37. Noor, M.A., Noor, k I., Mohyud-din, S.T.: Variational iteration method for solving sixth-order boundary value problems. Commun. Nonlinear Sci. Numer. Simul. 14, 2571-2580 (2009)

38. Abdou, M.A., Soliman, A.A.: Variational iteration method for solving Burgers' and coupled Burgers' equations. J. Comput. Appl. Math. 181, 245-251 (2005)

39. Ahmed, N., Khan, U., Zaidi, Z.A., Jan, S.U., Waheed, A., Mohyud-din, S.T.: MHD flow of an incompressible fluid through porous medium between dilating and squeezing permeable walls. J. Porous Media 17(10), 861-867 (2014)

40. Khan, U., Ahmed, N., Zaidi, Z.A., Jan, S.U., Mohyud-Din, S.T.: On Jeffery-Hamel flows. Int. J. Mod. Math. Sci. 7, 236-247 (2013)

41. Khan, U., Ahmed, N., Khan, S.I.U., Zaidi, Z.A., Yang, X.J., Mohyud-Din, S.T.: On unsteady twodimensional and axisymmetric squeezing flow between parallel plates. Alex. Eng. J. 53, 463-468 (2014)

42. Khan, U., Ahmed, N., Zaidi, Z.A., Asadullah, M., Mohyud-Din, S.T.: MHD squeezing flow between two infinite plates. Ain Shams Eng. J. 5, 187-192 (2014)

43. Khan, U., Ahmed, N., Khan, S.I.U., Bano, S., Mohyud-Din, S.T.: Unsteady squeezing flow of Casson fluid between parallel plates. World J. Model. Simul. 10(4), 308-319 (2014)

44. Khan, U., Ahmed, N., Asadullah, M., Mohyud-Din, S.T.: Effects of viscous dissipation and slip velocity on two-dimensional and axisymmetric squeezing flow of $\mathrm{Cu}$-water and $\mathrm{Cu}$-kerosene nanofluids. Propul. Power Res. Accepted

45. Zaidi, Z.A., Jan, S.U., Ahmed, N., Khan, U., Mohyud-Din, S.T.: Variation of parameters method for thin film flow of a third grade fluid down an inclined plane. Ital. J. Pure Appl. Math. 31, 161-168 (2013)

46. Motsa, S.S., Sibanda, P., Awad, F.G., Shateyi, S.: A new spectral-homotopy analysis method for the MHD Jeffery Hamel problem. Comput. Fluids 39, 1219-1225 (2010)

47. Motsa, S.S., Sibanda, P., Marewo, G.T.: On a new analytical method for flow between two inclined walls. Numer. Algorithms 61, 499-514 (2012)

48. Khan, W.A., Khan, Z. H., Rahi, M.: Fluid flow and heat transfer of carbon nanotubes along a flat plate with Navier slip boundary, Appl. Nanosci. doi:10.1007/s13204-013-0242-9 